\title{
Use of the total artificial heart as a bridge to transplant in a 13-year-old with congenitally corrected transposition of the great arteries
}

\author{
Ming-Sing Si, MD, ${ }^{\mathrm{a}}$ Francis D. Pagani, MD, PhD, ${ }^{\mathrm{b}}$ and Jonathan W. Haft, MD, ${ }^{\mathrm{b}}$ Ann Arbor, Mich
}

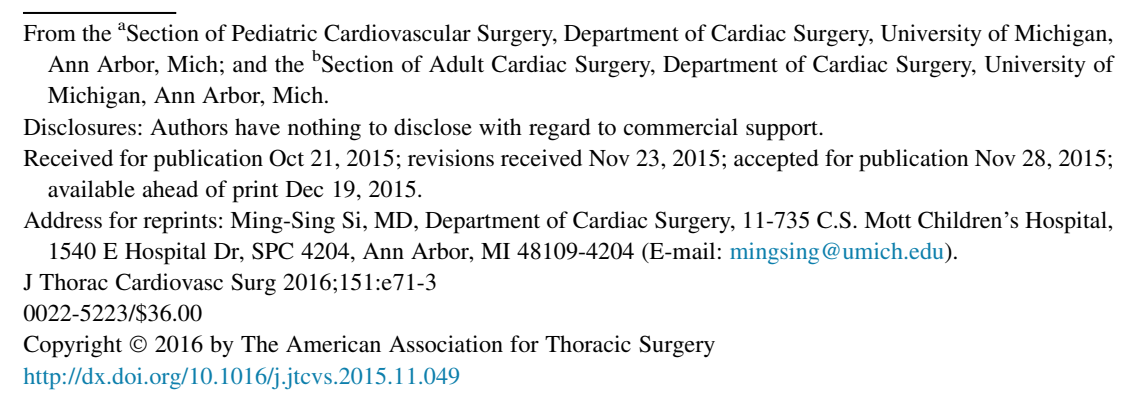

Without anatomic correction, the systemic right ventricle (RV) and tricuspid valve are prone to failure in patients with congenitally corrected transposition of the great arteries (CCTGA). ${ }^{1}$ Left ventricular function may also be depressed in these patients, resulting in biventricular failure. $^{2}$

\section{CLINICAL SUMMARY}

A 13-year-old boy (body surface area $1.8 \mathrm{~m}^{2}$ ) with dextrocardia, $\{$ S,L,L $\}$ CCTGA, ventricular septal defect, pulmonary stenosis, Ebsteinoid tricuspid valve with severe regurgitation, and pulmonary hypertension (Figures 1 and 2) was seen at the University of Michigan. Pulmonary hypertension was elevated (but reactive to inhaled nitric oxide from 8 to 4 Wood units), and a heart transplant was therefore considered to carry a higher risk than anatomic repair. The patient underwent a SenningRastelli procedure and RV-to-pulmonary artery conduit placement (Hancock; Medtronic, Inc, Minneapolis, Minn). RV pressures immediately after repair were half of systemic pressures. On postoperative day (POD) 0 , the patient had biventricular failure as a result of diastolic dysfunction (central venous and left atrial pressures $>20 \mathrm{~mm} \quad \mathrm{Hg}$ ) and required venoarterial extracorporeal membrane oxygenation support. The patient was successfully weaned on POD 4; however reinstitution of extracorporeal membrane oxygenation was necessary 3 days later for worsening diastolic failure and was maintained for 8 more days, with multiple unsuccessful attempts at weaning.

Bridge to transplant with a total artificial heart (TAH; Syncardia Systems, Inc, Tuscon, Ariz) was undertaken (Figure 3). During TAH implantation, the Senning pathway was reversed. The 70-cc TAH ventricles were implanted with the pulmonary outflow connected to the RV-to-pulmonary artery conduit. TAH settings were as

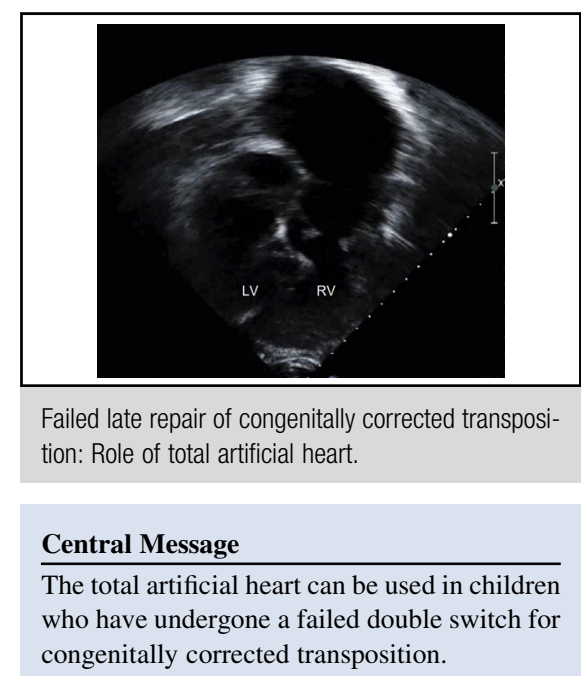

See Editorial Commentary page e73.

follows: left ventricular drive pressure, $190 \mathrm{~mm} \mathrm{Hg}$; $\mathrm{RV}$ drive pressure, 70 to $80 \mathrm{~mm} \mathrm{Hg}$; vacuum, 11 to $12 \mathrm{~mm} \mathrm{Hg}$; beat rate, 100 beats/min; and cardiac output, $5.3 \mathrm{~L} / \mathrm{min}$. A small decrease in $\mathrm{RV}$ drive pressure and vacuum were made on the basis of the appearance of the chest radiograph and fluid mobilization. Anticoagulation was accomplished with aspirin, heparin, warfarin sodium, and dipyridamole. Fibrinogen levels were 244 to

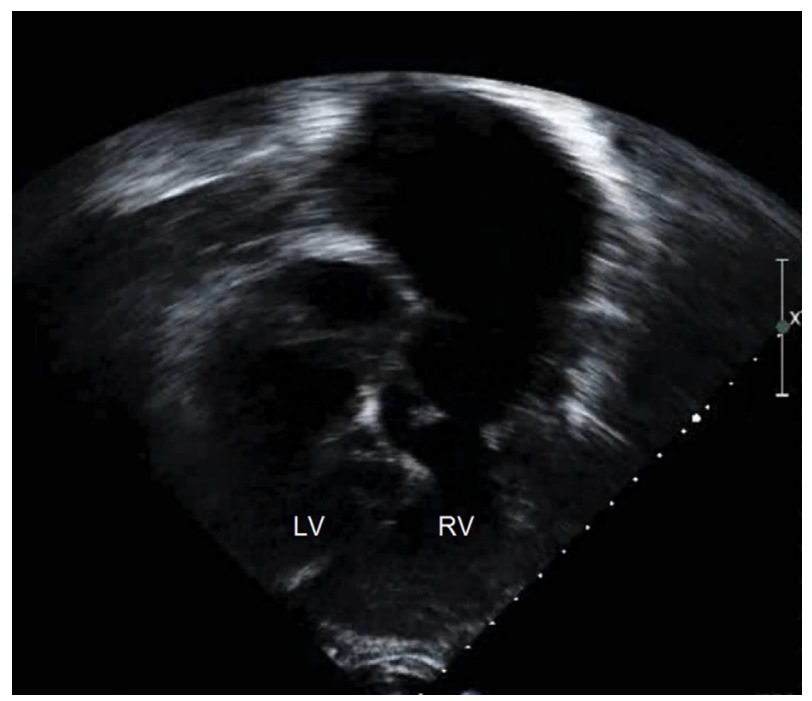

FIGURE 1. Echocardiogram demonstrating a systemic right ventricle $(R V)$, pulmonary left ventricle $(L V)$, and severe left atrial dilation. 

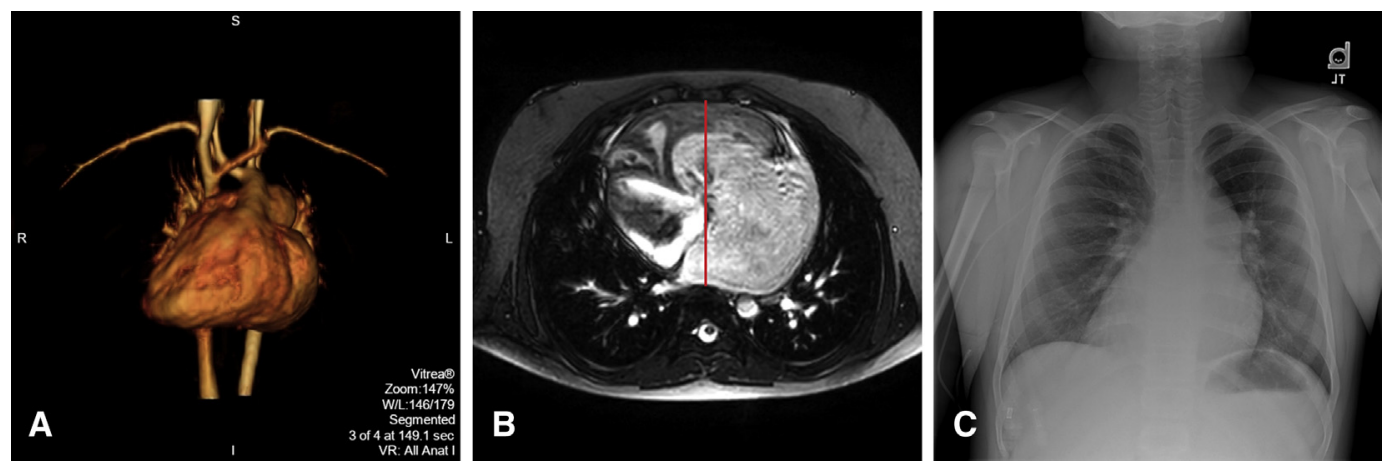

FIGURE 2. A, Three-dimensional reconstruction of cardiac magnetic resonance image demonstrating congenitally corrected transposition of the great arteries and dextrocardia. B, Axial cardiac magnetic resonance image demonstrating cardiomegaly and anteroposterior mediastinal dimension of $12 \mathrm{~cm}$ at the level of the pulmonary veins. C, Preoperative chest radiograph demonstrating dextrocardia and cardiomegaly.

$391 \mathrm{mg} / \mathrm{dL}$, and platelet concentrations were 84 to $208 \times 10^{3}$ cells $/ \mu \mathrm{L}$.

A suitable donor graft became available on POD 8, and the patient underwent explantation of the TAH and an orthotopic heart transplant. No thrombus was noted in the TAH at explantation. The ascending aorta and hemiarch were also replaced because of a deadventitializing injury that had occurred from cannulation at his original procedure. The patient was started on inhaled nitric oxide intraoperatively and was transitioned to sildenafil. Pulmonary vascular resistance was initially 15 Wood units $/ \mathrm{m}^{2}$ but decreased to 4.5 Wood units $/ \mathrm{m}^{2}$ by discharge. The patient was transferred to the ward on POD 16 after the transplant and was discharged on POD 24 (Figure 3).

\section{DISCUSSION}

Mechanical circulatory support device options for pediatric patients are limited. Because of this patient's size, the TAH was a suitable option. Biventricular diastolic dysfunction prevented the use of a systemic ventricular assist device. This is the second report of TAH use in a pediatric patient with CCTGA. A 17-year-old with CCTGA who had undergone a physiologic repair with subsequent TAH implantation required modification because of anatomical considerations. ${ }^{3}$ In our case, the only modification performed was that we left the distal portion of the RV-to-pulmonary artery conduit intact and anastomosed the right sided outflow graft to this. Further, we elected to reverse the Senning procedure because of the risk of obstruction of the pulmonary venous pathway after TAH implantation. Our patient tolerated the TAH without any adverse events. He did have a labile pre-transplant pulmonary vascular resistance; however, we did not consider this severe enough to outweigh the risk of postponing his transplant (increased time on the device and the potential development of severe adhesions). To our knowledge, Park and colleagues ${ }^{4}$ have reported the only other successful case of pediatric TAH use, in a
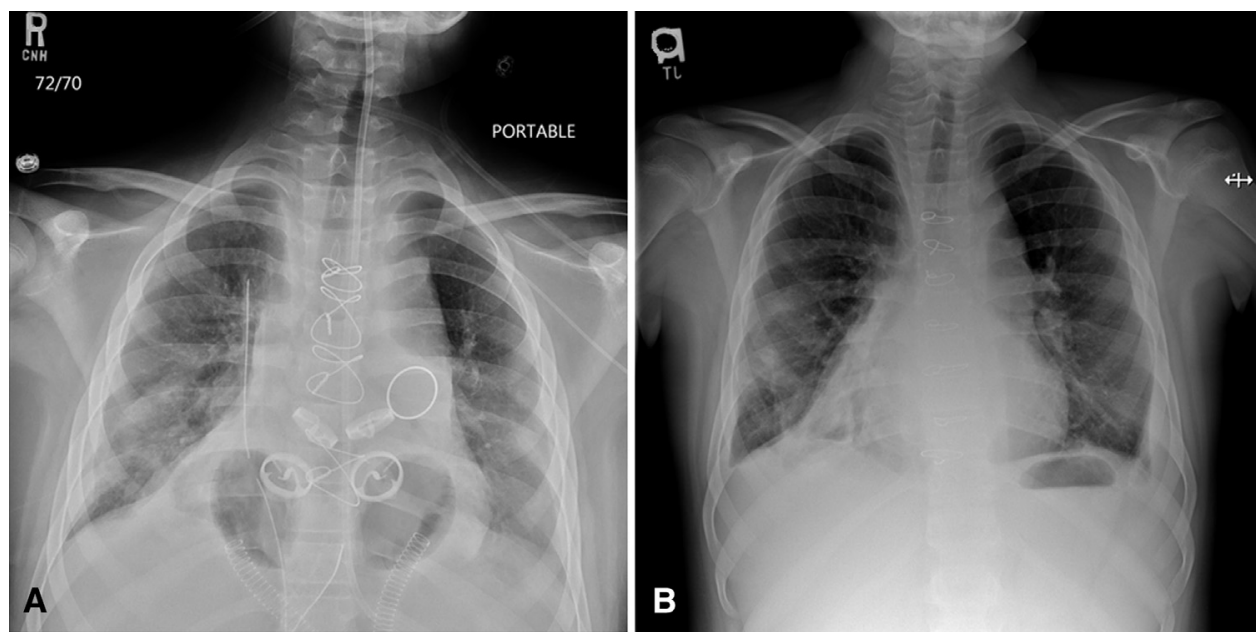

FIGURE 3. A, Post-total artificial heart implant chest radiograph demonstrating the 4 mechanical valves of the total artificial heart ventricles and the reinforcement ring of the right ventricle-to-pulmonary artery conduit. B, Posttransplant chest radiograph demonstrating removal of total artificial heart and right ventricle-to-pulmonary artery conduit. 
14-year-old with dilated cardiomyopathy. With the advent of the 50-cc TAH, we anticipate that this device will benefit pediatric patients with end-stage, complex congenital heart disease. $^{5}$

\section{References}

1. Wallis GA, Debich-Spicer D, Anderson RH. Congenitally corrected transposition. Orphanet J Rare Dis. 2011;6:22.

2. Giardini A, Lovato L, Donti A, Formigari R, Oppido G, Gargiulo G, et al. Relation between right ventricular structural alterations and markers of adverse clinical outcome in adults with systemic right ventricle and either congenital complete (after Senning operation) or congenitally corrected transposition of the great arteries. Am J Cardiol. 2006;98:1277-82.

3. Morales DL, Khan MS, Gottlieb EA, Krishnamurthy R, Dreyer WJ, Adachi I Implantation of total artificial heart in congenital heart disease. Semin Thorac Cardiovasc Surg. 2012;24:142-3.

4. Park SS, Sanders DB, Smith BP, Ryan J, Plasencia J, Osborn MB, et al. Total artificial heart in the pediatric patient with biventricular heart failure. Perfusion. 2014;29:82-8.

5. Ryan TD, Jefferies JL, Zafar F, Lorts A, Morales DL. The evolving role of the total artificial heart in the management of end-stage congenital heart disease and adolescents. ASAIO J. 2015;61:8-14.

\title{
EDITORIAL COMMENTARY
}

\section{The total artificial heart in pediatrics: Expanding the repertoire}

\author{
Eric J. Devaney, MD
}

\footnotetext{
From the Department of Surgery, Rady Children's Hospital-San Diego, San Diego, Calif. Disclosures: Author has nothing to disclose with regard to commercial support.

Received for publication Dec 18, 2015; accepted for publication Dec 19, 2015; available ahead of print Feb 18, 2016.

Address for reprints: Eric J. Devaney, MD, Department of Surgery, Rady Children's Hospital-San Diego, 3030 Children's Way, MOB \#202, San Diego, CA 92123 (E-mail: edevaney@ucsd.edu).

J Thorac Cardiovasc Surg 2016;151:e73-4

$0022-5223 / \$ 36.00$

Copyright (C) 2016 by The American Association for Thoracic Surgery

http://dx.doi.org/10.1016/j.jtcvs.2015.12.039
}

Experience with the total artificial heart (TAH) in the pediatric population has been limited to date. Sizing recommendations for implantation of the Syncardia 70-cc ventricles generally include a body surface area $(\mathrm{BSA})>1.7 \mathrm{~m}^{2}$ and an anteroposterior dimension (from sternum to T10 vertebra) $>10 \mathrm{~cm}$. ${ }^{1}$ The pericardial space must be sufficient to accommodate this sizeable device without causing venous compression, which invariably compromises device filling. The recent development of imaging software that can simulate device implantation can aid preoperative decision making for small or borderline-sized patients. ${ }^{2} \mathrm{Un}$ til recently, TAH recipients required in-hospital care, but the introduction of a compact portable driver has improved patient mobility and now allows discharge to home.

Patients with congenital heart disease have demonstrably worse outcomes following left ventricular assist device implantation (especially single-ventricle patients), and the need for biventricular support confers additional risk. The TAH offers the prospect of complete restoration of hemodynamics, and wider availability of the TAH will perhaps level the playing field and improve the bridge to transplant statistics in this group of patients. Support for this proposition remains precarious, however. Worldwide, among more than 1000 TAH implants, pediatric implants accounted for $<5 \%$, and

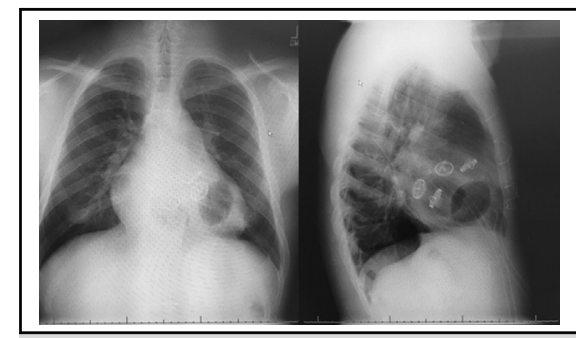

PA and lateral radiography after Syncardia TAH implantation.

Central Message

The use of the Syncardia TAH in pediatrics, especially for congenital heart disease, is likely to increase.

See Article page e71.

implants for congenital heart disease (all ages), only $2 \%$. It is encouraging that $100 \%$ of adolescent patients with congenital heart disease (albeit only 7 patients, including the patient described in the current report) have been successfully bridged to transplantation with a TAH. ${ }^{3,4}$ Realistically, experience with the TAH in adults reveals outcomes similar to those seen with biventricular assist therapy.

Syncardia has designed a smaller version of the TAH with 50-cc ventricles, planned for use in diminutive adults and adolescents down to a BSA of $1.2 \mathrm{~m}^{2}$. Following approval, this device should dramatically expand use of the TAH in the pediatric population. As with the adoption of VAD technology, pediatric centers will benefit from the experience achieved by adult programs that use TAH technology. Further clinical use will necessarily define the appropriate 